\title{
Accessibility and site suitability for healthcare services using GIS- based hybrid decision-making approach: a study in Murshidabad, India
}

\author{
Farhana Parvin $^{1}\left(\mathbb{D} \cdot\right.$ Sk Ajim Ali $^{1} \cdot$ S. Najmul Islam Hashmi ${ }^{1}$ Aaisha Khatoon ${ }^{2}$
}

Received: 10 February 2020/Revised: 17 April 2020/Accepted: 23 April 2020/Published online: 11 May 2020

(C) Korean Spatial Information Society 2020

\begin{abstract}
Healthcare accessibility and site suitability analysis is an elongated and complex task that requires evaluation of different decision factors. The main objective of the present study was to develop a hybrid decisionmaking approach with geographic information systems to integrate spatial and non-spatial data to form a weighted result. This study involved three-tier analyses for assessing accessibility and selecting suitable sites for healthcare facilities, and analysing shortest-path network. The first tier of analysis stressed the spatial distance, density and proximity from existing healthcare to find more deprived and inaccessible areas in term of healthcare facilities. The result revealed that spatial discrepancy exists in the study area in term of access to healthcare facilities and for achieving equal healthcare access, it is essential to propose new plans. Thus, require finding suitable sites for put forward new healthcare service, which was highlighted in the second tier of analysis based on land use land cover, distancing to road and rail, proximity to residential areas, and weighted overlay of accessibility as decision factors. Finally, in the third tier of analysis, the most suitable site among the proposed healthcare was identified using the technique for order of preference by similarity to ideal solution. The road network analysis was also performed in
\end{abstract}

Electronic supplementary material The online version of this article (https://doi.org/10.1007/s41324-020-00330-0) contains supplementary material, which is available to authorized users.

Farhana Parvin

farhanaparvin93@gmail.com

1 Department of Geography, Faculty of Science, Aligarh Muslim University, Aligarh, UP 202002, India

2 Department of Commerce, Faculty of Commerce, Aligarh Muslim University, Aligarh, UP 202002, India this study to determine the shortest and fastest route from these healthcare facilities to connect with district medical hospital. The present study found some suitable sites throughout the district on inaccessible zones where people are deprived from better healthcare facilities. This attempt will highly helpful for preparing a spatial decision support system which assists the health authorities regarding the healthcare services in inaccessible, underprivileged, and rural areas.

Keywords Geographic information system - Healthcare accessibility $\cdot$ Site suitability $\cdot$ Hybrid decision-making approach

\section{Introduction}

The terminology of accessibility possesses the multi-layered and multi-faceted concepts which ascertain the quality of admitting approaches which provide a range of support services. Potential accessibility ensures the optimum access to comprehensive and quality healthcare to every single individual of a population within a short of healthcare service providers [1]. Adequate accessibility to healthcare service is one of the vital elements for holding an advanced society status. Thus, it holds a position in the 17 th global targets set by the United Nations for promoting sustainable development goals [2]. WHO under the human right concept describe accessibility as availability of health services within a safe and reasonable physical reach to all section of the population especially vulnerable and marginal groups likely ethnic minorities and indigenous people, women, children, aged groups and persons with disabilities including in rural areas [3]. A United States President's Commission in 1983 sort to explain the meaning and 
conceptual problem related to accessibility that equitable access to healthcare should be in a manner that every single citizen can acquire an adequate level of medical care without excessive burdens [4]. Another Commission came with a solution regarding the conceptual problems related to access and gave a comprehensible answer that the concept of accessibility is as important as the usage of service for health outcomes. Their definition relies on both the concept of timely use of healthcare services and on the best possible use of health outcome [5].

In a society, expenditure on healthcare is considered as the best social investment as healthy society is one of the fundamental aspects of development to promote social well-being and to minimize health disaster risk in many developing countries [6, 7]. In India, despite economic advancement, inequality in healthcare is one of the primary challenges to meet development goal [8]. Several Committees are set up to recommend public health policy aims to provide high-quality equal healthcare service to all likely Bhore committee 1946, Ministry of Health and Family Welfare 2012, National Urban Health Mission 2013 [9]. Despite all these efforts, a recent health survey reveals that only about $29 \%$ of Indian Population is served in Government Hospitals and about one-fourth income of each household has been invested in healthcare services [1].

Many studies attempt various techniques to get a clear understanding of the accessibility to healthcare centre and to delineate the deprived regions of these healthcare facilities [10]. Geospatial techniques are widely used in different field of studies related to healthcare for maximizing the geographical accessibility to medical services [11]. GIS is a platform which provides a framework in relation to the population for both assessments of the distribution of healthcare centres and evaluation of effective coverage [12]. Spatial or geographical accessibility generally refers to the physical access of a user to a provider's location [13] or simply reflect the linkages between the point of supply and point of demand by taking consideration of existing transport framework and travel impedance [14]. Accessibility is a multidimensional concept which inherent both spatial dimension such as availability, accessibility and non-spatial dimensions like affordability, acceptability and accommodation [15, 16]. Khan [16] highlighted the vehicular travel time/distance and Euclidean distance for characterising spatial attributes to measure spatial accessibility. Spatial separation based model is a suitable approach when there is incomplete and lacking transport network data and give desirable result for accessibility operation by using the physical distance between infrastructures as it only uses the location of services of interest [17]. Cumulative opportunity or isochrones approach is an effective method as it considers the elements of travel time as well as maximum desirable travel time by capturing land use pattern and infrastructural barrier across the land cover. Gravity Model is another model for operating accessibility provides the size of the zone of interest, the configuration of the zone, choice of attractor variables and the values of travel impedance time. Besides these approaches, the two-step floating catchment area was (2SFCA) proposed by Luo and Wang for calculating spatial accessibility [18]. In this method, a floating catchment area is selected as a window to measure serviceto-population ratio for each healthcare service. After that, the entire ratio is summed up for each point of location within the catchment area and use it as an accessibility index of that location. Enhanced two steps floating catchment area method come to overcome the rigidity and arbitrariness of the 2SFCA i.e. it does not take into account the distance decay method, it sets catchment and subzones of healthcare by considering travel time or travel distance based on the road network is often used as the spatial barrier or impedance [19]. Three steps floating catchment area method used by Rekha et al. [1] to calculate accessibility by considering three attributes namely attractiveness of health services, travel time and distance between the location of the service centre and the location of residents and population demand for healthcare facilities.

These all techniques have its advantages in term of application but the result will be incredible if geographic information system (GIS) integrated for the spatial result. GIS application in healthcare accessibility measurement is exclusively popular for two decades [20]. GIS is one of the sophisticated spatial analyst techniques that not only potential to identify demand flexible points based on residential clustering but also pinpoint spatial inequalities in healthcare delivery points and provide suitable locations for new health facilities [11]. The geographical dimension of access can be authentically expressed by GIS and appreciate the fact that GIS technique has potential to fit in a wide range of aspects such as identification of vulnerable population who are devoid of service reach, delimit the points of quality service and treatment without looking at the loopholes in previous qualitative research [21]. Several studies found that GIS technique is very useful in the demarcation of nearest healthcare centre for different road network by using patient's postal/zip code and converted then into grid reference to find straight line or travel time distance [11, 22]. Geographical information system applied to measure the relative importance of distance on providers to gain treatment for depression and also tried to understand the barriers regarding the adaptation of such medical facilities in rural as well as urban areas [23]. Distance and travel time are the most important factor for serving people because the number of death increases with increasing travel time to a hospital in a region [24]. GIS offers a 
distance tool to estimate travel time between healthcare and residential premises and also deals with the shortest and fastest path analysis to reach nearby healthcare in a short time interval.

Looking towards such advantages of geographic information system and geospatial analysis, the present study also emphasized and applied a hybrid decision-making approach with the support of GIS. The present study aimed to utilize spatial tools to integrate different spatial and aspatial information for spatial analysis of healthcare accessibility and inaccessibility which support to propose new health infrastructures in inaccessible areas in Murshidabad district of West Bengal, India. Such type of geospatial analysis for healthcare accessibility would be applied for identifying suitable sites and allocating new service areas, determining most ideal sites where allocation requirement has essential, and estimating the shortest and fastest distance between nodes of healthcare facilities. The study also offers assistance to health authorities to understand spatial pattern and distribution of healthcare availabilities and facilities for better service to inaccessible and deprived areas.

\section{Materials and methods}

\subsection{Case study area}

Murshidabad district (West Bengal, India) is one of the classical provinces with rich historical background and also an important unit of the state, as it shares the largest international boundary with Bangladesh in its eastern part. It is the northernmost district of presidency division of West Bengal geographically lying between $23^{\circ} 432^{\prime} \mathrm{N}$ and $24^{\circ} 52^{\prime} \mathrm{N}$ and $87^{\circ} 49^{\prime} \mathrm{E}$ and $88^{\circ} 44^{\prime} \mathrm{E}$ (Fig. 1). The district HQ is Behrampore. The district is boarded by Burdwan and Nadia district in the south and Birbhum district and Jharkhand state in the west and Malda district in the north. River Bhagirathi divides the entire district almost two equal parts, popularly known as 'Radh' on the western side and 'Baghri' on the western side. The total area of the district is $5324 \mathrm{~km}^{2}$ and holds the 7th largest position among the districts of the states in terms of land area.

According to the 2011 census, Murshidabad district is home of around 7,102,430 people which is roughly equal to the total population of Bulgaria and United states of Washington [25]. Population density of the district is $1334 / \mathrm{km}^{2}$ and the decadal growth rate is $21.07 \%$. The district has a large concentration of minority population which accounts $66 \%$ of the total population of the state where the majority are Muslims; the sex ratio is 957 per 1000 males and literacy is $67.53 \%$ with a male and female literacy rate of 69.95 and 63.09 respectively. This district is a rural unit and a large number of the total workers accounts for $34.77 \%$ of the total population engaged in other works such as labourer [26], followed by agricultural labourers i.e. $32.52 \%$ and household industry workers contributing to $17.99 \%$. The above statistics on literacy, male-female ratio of literacy, and worker pattern indicate that this region is not well developed in term education and occupation. As far as the healthcare facilities are concerned, the district depicts a deprived health service profile where only one medical college and hospital is situated with a bed occupancy rate of 139.8. There is only three super-specialist hospital and four sub-division hospitals are present with a bed occupancy rate of 97.5 and 127.55 respectively [27]. Rural hospital and public healthcare are also available but the service qualities are not well. Moreover, the accessibility of these healthcare facilities is also a vital concern and need to bring focus on proper access to present institutions and also the elimination of disparity region.

\subsection{Existing healthcare facilities}

Accessibility has a shorthand terminology with longhand sets of assignments for potential utilization of healthcare services which estimates the degree to which all individual of a population can reach needed services present within the defined distance or driving time. Availability, affordability is another important component of healthcare utilization. Optimal exercise of healthcare facilities assessment is not an easy task and can be done by estimating location-based accessibility and individual-based accessibility. Spatial distribution of public health services illustrates a healthcare profile of any space. Murshidabad district has an average portrait of medical services where availability of health institutions is not quite unacceptable but accessibility in terms of a positive outcome is not adequate. A positive outcome can be assessed through efficient treatment, adequacy of a speciality hospital, proper diagnostic and treatment skills of the provider. Lack of this positive outcome makes an accessible profile of the district poor.

Murshidabad district come under the medium-to-low accessible zone for health service if only availability of medical institution will be the criteria but spatial location (distance, travel impedance, travel cost etc.) of the healthcare centres also a vital element for driving accessibility. The district has many government hospitals and public nursing homes under different categories such as one medical college and hospital, super specialist hospitals, sub-divisional hospitals, rural hospitals, and nursing homes. Murshidabad district has 26 blocks under 5 subdivisions where the spatial distribution of healthcare centres is not advantageous as there is a trend of clustering can 


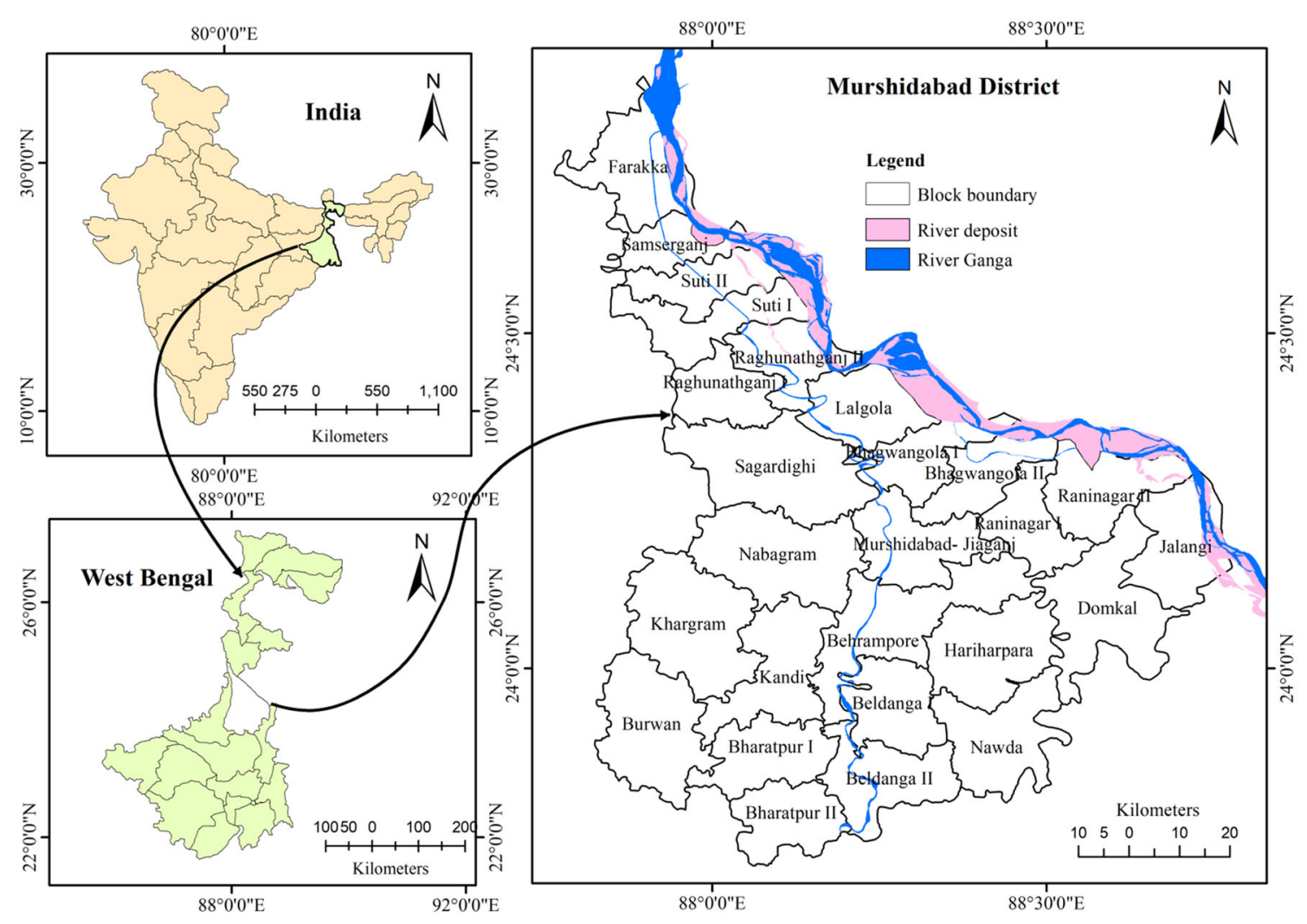

Fig. 1 Location map of the case study area

be found. Maximum clustering of medical centres is found in certain blocks only such as Behrampore, MurshidabadJiaganj, Domkal, Raghunathganj-I (Table 1). Behrampore block is the highest accessible area of the district where a cluster of many medical institutions are placed including medical college and hospital, public healthcare centres. Suti-I, Raghunathganj-II, Sagardighi, Bhagwangola-II, Raninagar-II, Jalangi and Bharatput-I blocks are the most inaccessible units of the district where a number of medical institution are very limited and rest of the block has moderate healthcare accessibility in terms of total medical institution establishment [26].

Healthcare accessibility is also illustrated by the efficiency of services which depends on the availability of the doctor. Doctor-patient ratio is one of the most important mediating factors for individual-based accessibility. Overburden of patients can lead to inappropriate treatment regimens due to inadequate doctor availability. Out of 26 blocks, only 6 blocks possess good accessibility such as Behrampore, Raghunathganj-I, Murshidabad Jiaganj, Domkal, Kandi, Beldanga-I blocks contains a good number of doctors among them Behrampore has the highest number of doctors i.e. 241. Remaining blocks have an inadequate number of doctors and possess low accessibility characteristics [26].
A number of patients are another accelerating factor for visualization of healthcare status. Behrampore block is still in the highest position in terms of a number of patients comes for treatment. A large number of patient in any healthcare centre can depict bilateral assumptions as one can be the better medical service attract the most of the patient and other can be the lack of sufficient medical institution can lead to high occupancy and burden rate. In the case of Murshidabad district, the second one can be the accelerating factor. Murshidabad-Jiaganj, Rghunathganj-I, Kandi, Nawda have experience high accumulation of patients, while Raninagar-I, Domkal, Hariharpara, Beldanga-I, Nabagram have a medium rate of patients crowd. Rest of the blocks such as Farakka, Samserganj, Suti-I and II, Raghunathganj-I and so on have comparatively less number of patients as most of the patient use cross-border medical facility due distance from district medical college and hospital.

Although potential accessibility of healthcare service can not only be measured by single criteria or indicator as all the indicators are interdependent to each other to accelerate higher accessibility. An adequate number of the medical institution with sufficient appointment of doctors available to fulfil patients medical needs can promote higher healthcare status of any unit, if one indicator overburdens the other, the balanced will disturb and can be a 
Table 1 Existing healthcare facilities and relative accessibility index. Source: Computed using the data of district statistical handbook2014

\begin{tabular}{|c|c|c|c|c|c|}
\hline Name of block & Area $\left(\mathrm{km}^{2}\right)$ & TMI & TPA & TDA & RAI \\
\hline Farakka & 132.74 & 5 & 43,032 & 4 & 0.0464 \\
\hline Samserganj & 84.21 & 6 & 190,626 & 6 & 0.0188 \\
\hline Suti-I & 143.68 & 3 & 129,911 & 4 & 0.0092 \\
\hline Suti-II & 111.13 & 5 & 114,450 & 6 & 0.0262 \\
\hline Raghunathganj-I & 140.91 & 12 & 380,951 & 29 & 0.0913 \\
\hline Raghunathganj-II & 121.6 & 2 & 114,117 & 6 & 0.0105 \\
\hline Sagardighi & 345.42 & 4 & 211,888 & 7 & 0.0132 \\
\hline Lalgola & 184.37 & 6 & 165,189 & 9 & 0.0326 \\
\hline Bhagwangola-I & 136.1 & 7 & 172,734 & 7 & 0.0283 \\
\hline Bhagwangola-II & 175.26 & 3 & 160,918 & 4 & 0.0074 \\
\hline Murshidabad-Jiaganj & 192.13 & 21 & 512,888 & 35 & 0.1433 \\
\hline Nabagram & 306.63 & 8 & 248,108 & 10 & 0.0322 \\
\hline Domkal & 305.19 & 19 & 338,406 & 28 & 0.1572 \\
\hline Jalangi & 210.63 & 3 & 100,105 & 3 & 0.0089 \\
\hline Raninagar-I & 146.93 & 7 & 259,732 & 5 & 0.0134 \\
\hline Raninagar-II & 175.13 & 4 & 149,176 & 8 & 0.0214 \\
\hline Behrampore & 314.19 & 40 & $1,092,278$ & 241 & 0.8825 \\
\hline Beldanga-I & 168.75 & 11 & 322,312 & 15 & 0.0511 \\
\hline Beldanga-II & 207.93 & 6 & 180,479 & 8 & 0.0265 \\
\hline Nowda & 231.39 & 8 & 374,436 & 9 & 0.0192 \\
\hline Hariharpara & 253.14 & 6 & 273,915 & 9 & 0.0197 \\
\hline Kandi & 227.48 & 9 & 445,334 & 38 & 0.0767 \\
\hline Khargram & 318.45 & 6 & 146,236 & 6 & 0.0246 \\
\hline Burwan & 299.66 & 7 & 162,798 & 8 & 0.0343 \\
\hline Bharatpur-I & 183.72 & 3 & 172,231 & 8 & 0.0139 \\
\hline Bharatpur-II & 158.5 & 6 & 164,081 & 8 & 0.0292 \\
\hline
\end{tabular}

(1) TMI total no. of medical institutions in respective block, TPA total no. of patients admitted in a year; $T D A$ total no. of doctors available per day, $R A I$ relative accessibility index

(2) High value of RAI indicates high accessible to health care and vice versa dynamic force for inaccessibility. For this purpose, a relative accessibility index (RAI) is a crucial factor for assessing the rate of accessibility of any region. Murshidabad district has possession of low relative accessibility index. Only a few pockets have high relative accessibility index such as Behrampore (highest), Murshidabad-Jiaganj, and Domkal, while rest of the blocks have low to very low status in terms of RAI (Table 1).

\subsection{Models on healthcare services}

Access to healthcare is a multi-fold concept and it mainly corresponds with many dimensions like availability, affordability, acceptability and geographical accessibility of the services. Geographical accessibility and availability of healthcare services contain spatial dimension which can be analysed by geographical information system while the rest two i.e. affordability and acceptability are non-spatial dimensions. Many types of research have been done to achieve higher accessibility to healthcare service mainly under the four notions: distance from the system works under two concepts i.e. nearest service centre to the population and average distance to the set of service centres, the threshold of the service, gravitational models for providers. Distance is the major element to calculate higher accessibility to the service. Sometimes it can be measured trough nearest location to the population, travel cost, travel time. Nearest the location of a service centre lesser the travel time and will minimize the travel cost, ultimately provide higher accessibility. Travel cost and the travel time will also be considered as an important element to measure the non-spatial dimension. Geographical information system (GIS) studies commonly used Euclidean distance method to calculate nearest the location of a service centre i.e. distance from a population centre [1]. This method faces drawback to provide suitable site mainly in urban areas where the population enjoys sets of service options within a certain point or point of reference. Thus, average 
travel impedance to the service will be suited to ensure spatial accessibility as it incorporates both the entities; accessibility and availability to the population. The threshold of the service can be calculated by several patients per medical institutions. It also refers to the supply options which incorporates doctor-patient ratio, number of bed per person. This method can be shown by density analysis (Point, Line, Kernel density) in GIS researches. This method also has some demerits as it does not consider the cross-border population demand to reference supply point. The gravity model is an updated version on Newton's law of gravity to analyse the spatial accessibility. This model overcomes the problems associated with former dimensions. It incorporates accessibility and availability of services within both rural and urban settings. It also helps to set the potential supply options to a certain set of potential population point. This model is thus:

$S_{k}=\sum_{j=1}^{n} \frac{S_{j} d_{i j}^{-\beta}}{V_{j}}$

But the main problem with this is the distance decay coefficient $\beta$, which is usually not known and expressed in term of linear or exponential.

Two-step floating catchment area model: floating catchment area model was primarily employed by Peng to analyse urban employment accessibility and further Luo and Wang also used this method to overcome problem arise for the gravity-based model to calculate spatial accessibility like quality and spatial resolution [1]. In this method, a catchment area selection is required based on distance and travel time and a spatial accessibility value is appointed for each population point by adding up to the service-population ratio of all the catchments overlay on the point. Following is the equation for measuring two-step catchment areas:

For healthcare service: $\quad H_{j}=\frac{S_{j}}{\sum k \in\left\{\operatorname{Dist}(k, j) \leq d_{o}\right\} P_{k}}$

For population point: $\quad P_{i}^{J}=\sum k \in\left\{\operatorname{Dist}(i, j) \leq d_{o}\right\} H_{j}$

where $P_{k}$ is the population size at point k, $H_{j}$ is the doctorpatient ratio, $S_{j}$ is the capacity of a particular healthcare centre, $d_{o}$ is the minimum travel time.

But this method is imitated on selected catchment areas and not suitable for all areas. Spatial accessibility value at the centre and periphery is higher and becomes zero just over the line. An intervention like flexibility in travel time can make variations in estimated spatial accessibility value. Thus, a more improved method is needed to overcome this problem.

Enhanced two-step floating catchment area model: In this model, the whole catchment area is divided into several subzones with a distinct weight for accessibility, instead of fixing particular binary accessibility for the entire catchment area. Following is the equation for computing this method:

$$
\begin{aligned}
P_{j} & =\frac{S_{j}}{\sum r=1,2,3 \sum k \in D r^{P_{k W_{r}}}} \\
S_{i}^{J} & =\sum r=1,2,3 \sum k \in D r^{P_{k W_{r}}}
\end{aligned}
$$

where $P_{j}$ is the doctor-patient ratio, $S_{j}$ is the capacity of the healthcare centre measured by bed availability or the number of doctors and $W_{r}$ is the accessibility weight appointed for each subzone depended on the distance $d$ between the facility and population and also depend on intervention coefficient.

$C(d)=e^{\frac{d^{2}}{\beta}}$

This method also has certain limitation such as it does not take into account the fact that competition among the healthcare centres situated in a single catchment area. Thus, some modification has to require and need to develop a more improved version.

Three-step floating catchment area model: This model is the extension of the previous method. The catchment area is devoted to each healthcare facility as well as population. It takes into account the travel distance and travel time for computing accessibility weight for each catchment (healthcare site) area. To overcome the problem of assigning equal accessibility value to each medical institution, a comparison weight is assigned to each healthcare service based on travel distance and time $\mathrm{T}_{\mathrm{d}}$.

$T_{d}=\frac{W_{i j}}{\sum k \in\left\{\operatorname{Dist}(i, k)<d_{o}\right\} W^{i k}}$

Where $W_{i j}$ and $W_{i k}$ are Gaussian weights for service site $\mathrm{j}$ and population site $\mathrm{k}$. This selection weight was further taken up in the subsequent formulas used to compute the doctor-patient ratios and the accessibility score as:

For each service site: $\quad P_{j}=\frac{S_{j}}{\sum r=1,2,3 \sum k \in G k{ }^{P_{k W_{r}}}}$

For each habitation: $\quad S_{i}^{J}=\sum r=1,2,3 \sum k \in G i{ }^{P_{j w_{r}}}$

Where $S_{j}$ is the capacity of the health care facility j, $P_{j}$ is the threshold of the service computed for each health care facility, $P_{k}$ is the population of habitation $\mathrm{k}$ and $W_{r}$ is the weight computed for each habitation and health care facility.

But this technique also has some drawback and not satisfactorily accepted because only aspatial data have considered here but the availability of spatial data i.e. no. of health institutions in a particular area, the distance among them, density of health care in a particular area are 
not considered. Thus, a new and hybrid approach is required through which spatial and aspatial information can be analysed, assessed and evaluated for a whole geographical area.

\subsection{Hybrid decision-making approach for the present study}

To overcome all these problems present study tried to prepare a hybrid decision-making approach for higher healthcare accessibility assessment. In recent times, the geographical information system (GIS) is used to prepare a hybrid model in which all aspects can be covered and merged for analysis. The present study has been carried through several steps to precede the decision-making approach. Firstly, relative accessibility index (RAI) has been estimated based on the existing situation and available data on no. of the medical institution, number of patients and number of doctors i.e. doctor-patient ratio. The RAI of health care facilities is the indication of the areal proportion of health facilities which help in analysing accessibility and inaccessibility. For the same, Euclidean distance, kernel density and proximate had been analysed to support suitability analysis of healthcare sites using the weighted linear combination. Parallelly, TOPSIS was applied to ascertain the most suitable sites where new health care facilities could be built to reach maximum people to provide better health service. Finally, the shortest path network analysis was measured to connect and interlinked between existing and proposed healthcare. Initially, to start the first hierarchy of decision making approach the relative accessibility index was calculated. It is obtained using the following equation:

$R A I=\frac{M i * D j}{P i} * \theta$

where $M i$ is the no. of the medical institution, $P i$ is the no. of patients, $D j$ is the availability of doctors and $\theta$ is the constant equal to 100 .

\subsubsection{Euclidean distance}

Euclidean distance was measured among each healthcare presently existed. It is a measure of the true straight line distance estimation between two points ' $x$ ' and ' $y$ ' in Euclidean space or along the ' $x$ ' and ' $y$ ' axis. It can be described by is putting Pythagora's theorem in one dimensional and two-dimensional spaces where there is one variable describing each cell and can be expressed as:

$d=\sqrt{\left(x_{2}-x_{1}\right)^{2}+\left(y_{2}-y_{1}\right)^{2}}$
But in ' $n$ ' dimensional space or real-world scenario where each cell will have value ' $x$ ' for each variable, Pythagoras's theorem is difficult to work, thus it can be overcome by measuring the distance between points which is stated as:

$D_{x y}=\sum_{p=1}^{n}\left(x_{p x}-x_{p y}\right)^{2}$

where $D_{x y}$ is the distance between the points $x$ and $y$ which is equal to the sum from the first variable $(p=1)$ to the last variable (n), of the squares of the distance from each dimension.

\subsubsection{Kernel density}

Density was measured to show the spatial availability of healthcare in the study area. It is one of the spatial analyst tools in GIS environment for making density analysis of features in a neighbourhood around those features. It is a non-parametric technique generally used to visualize and analyse spatial data for mapping and estimating spatial pattern or event. Kernel density calculates both point and line features around each output raster cell which is calculated by considering the total number of the intersection of the individual features. Here the raster is calculated by the quadratic formula given by Silverman where the highest value is placed at the centre of surface features and pointing towards zero with distance at the search radius [28]. It can be calculated by using the equation:

$f(y)=\frac{1}{n h} \sum_{i=1}^{n} k\left(\frac{x-X i}{s}\right)$

Where ' $\mathrm{k}$ ' is the kernel function with density $f(y)$, ' $\mathrm{y}$ ' is the sampled data, ' $n$ ' is the number of sample and 's' is the smoothing parameter or say bandwidth.

\subsubsection{Proximity}

Proximity tool was used to discover spatial association of features. With this tool output information is gained through the buffer and multiple ring buffers which create an areal feature at a specific distance around the input features. Multiple buffers were linear for a small number of the foreclosed unit within various distance bands around a given point.

Present work presented a simple and efficient decisionmaking approach based on a structural and integrated method to deal with the decision-making problem. A novel group of hybrid decision-making framework has been built for evaluating accessible and inaccessible zone to healthcare services by integrating different raster layers i.e. 
Euclidean distance, kernel density, proximity to support the weighted linear combination.

\subsubsection{Weighted linear combination model}

Weighted linear combination method is a multi-parametric decision model and comes under one of the fundamental classes of multi-criteria evaluation method in GIS which follows the compensatory combination rules [29]. This method has been widely used in other studies also, like in land-use suitability analysis [30], in suitability analysis for soil erosion [29], diseases susceptibility [31-33] etc. Present work accepted this technique to identify accessible and inaccessible areas for health care by applying equal weight. All selected raster layers were reclassified with equal cell size to combine them into a single accessibility layer. A weighted linear combination is defined as:

$A=\sum_{i=1}^{n} W i * P i$

Where $W i$ is the weight value of deciding factor I, $P i$ is the selected raster input and $\mathrm{n}$ is the number of selected decision criteria.

\subsubsection{Site suitability analysis}

Suitable sites for proposing and allocating new healthcare was determined using suitability analysis. Site suitability is a process of allocation of new and ideal sites by analysing exiting site structure, pattern and condition based on several appropriate criteria. For this determination, the present study had prepared a suitable model for understanding appropriate location by integrating different thematic layers like road accessibility, railway network, land use land cover, and residential density. All these maps have been converted into raster so that each pixel can detect a score. It is important in suitability analysis to set a score for each category at $1-5$ or $1-9$ point scale as per their suitability. Thematic maps were combined into composite suitability.

For suitability analysis, first of all, land use land cover has been classified. Barren, fellow land and low economic and less resourceful land has been considered for highly suitable to allocate new health care. Secondly, the rail network and road accessibility have been considered for merging with the above-mentioned land category. Areas properly connected through road and rail was taken as a suitable site for such allocation. Parallelly, residential accessibility was also taken, $5 \mathrm{~km}$ buffer of areas having high population get more preference for suitable sites. This decision approach supported to propose 8 suitable sites for allocating new health care facilities in inaccessible areas. Among this which site is best suitable and where argent requires for allocating new health care is determined using TOPSIS analysis.

\subsubsection{TOPSIS analysis}

TOPSIS is the acronym of Technique for Order Preference by Similarity to Ideal Solution. This concept was first introduced by Hwang and Yoon in 1981 [34]. TOPSIS is one of the best multi-criteria decision-making methods used for selecting the best solution from decision criteria. There are adequate studies related to TOPSIS application [35]. Using TOPSIS, the ideal and non-ideal solutions are identified simultaneously. In the present study, TOPSIS was used to identify the best site among the proposed suitable sites for health care service. This method is quite simple which is presenting a satisfactory performance in different field of applications. The idea of TOPSIS procedure can be conveyed in a sequence of following steps [36].

Step 1 Prepare the decision matrix and determine the weight to decision criteria

Suppose, $\quad \mathrm{X}^{\mathrm{a}}=\left(x_{i j}^{a}\right)$ is a decision matrix, $\mathrm{Wk}=\left(w_{1}^{a}, w_{2}^{a}, w_{3}^{a}, \ldots w_{n}^{a}\right)$ is the weight vector for a-expert or decision-maker, where $w_{1}^{a}+w_{2}^{a}+w_{3}^{a}+\cdots+w_{n}^{a}=1$ ) and $\mathrm{a}=1,2,3, \ldots \mathrm{n}$. In a decision matrix, the linguistic term expresses low to excellent range, which has to convert using a 5 point scale in TOPSIS (Table 2).

The selected criteria of the decision making can be: benefit functions (more is a high preference) or non-beneficial (less is a high preference)

Step 2 Calculate the normalised decision matrix $\left(\bar{X}_{i j}\right)$. The Normalised value $\bar{X}_{i j}$ is expressed as:

$$
\bar{X}_{i j}=\frac{X_{i j}}{\sqrt{\sum_{i=1}^{n} X_{i j}^{2}}}
$$

Table 2 Rating of linguistic term using 5 point scale

\begin{tabular}{ll}
\hline Linguistic term (TOPSIS) & Scale value for rating \\
\hline Low & 1 \\
Below average & 2 \\
Average & 3 \\
Good & 4 \\
Excellent & 5 \\
\hline
\end{tabular}


Step 3 Calculate weighted normalised matrix by multiplying its associated weight. The weighted normalised value $V_{i j}$ is expressed as:

$V_{i j}=X_{i j} * W_{j}$

Step 4 Calculate the ideal best and ideal worst value

For ideal best : $\quad V_{j}^{+}=\left\{V_{1}^{+}, V_{2}^{+}, V_{3}^{+}, \ldots V_{j}^{+}\left(\frac{\max V_{i j}}{i} \in I^{\prime}\right),\left(\frac{\min V_{i j}}{i} \in I^{\prime \prime}\right)\right\}$

For ideal worst : $\quad V_{j}^{-}=\left\{V_{1}^{-}, V_{2}^{-}, V_{3}^{-}, \ldots V_{j}^{+}\left(\frac{\min V_{i j}}{i} \in I^{\prime}\right),\left(\frac{\max V_{i j}}{i} \in I^{\prime \prime}\right)\right\}$

where $I^{\prime}$ and $I^{\prime \prime}$ is associated with the ascent and descent factor respectively.

The ideal best and worst value is depending on the selected criteria. Here, for selecting a suitable site for health care service, the lower distance from the transportation route and the residential area will get the highest preference value and vice versa.

Step 5 Calculate the Euclidean distance from the ideal best

Now, the Euclidean distance has to calculate from the ideal best value, $S_{j}^{+}$.

$S_{j}^{+}=\left[\sum_{j=1}^{n}\left(V_{i j}-V_{j}^{+}\right)^{2}\right]^{0.5}$

Step 6 Calculate the Euclidean distance from the ideal worst

Same as ideal best, the ideal worst value, $S_{j}^{-}$.is as follows

$S_{j}^{-}=\left[\sum_{j=1}^{n}\left(V_{i j}-V_{j}^{-}\right)^{2}\right]^{0.5}$

\section{Step 7 Calculate Performance Score}

Finally, the preference score or relative closeness to the ideal solution is determined. The Pi is expressed by:

$P_{i}=\frac{S_{j}^{-}}{S_{j}^{+}+S_{j}^{-}}$

The higher $P_{i}$ the value indicates the best site for allocating propose health care infrastructure. TOPSIS is an efficient technique of multi-criteria decision analysis which emerges as a suitable technique for finding a suitable site and ideal solution.

\section{Results}

Murshidabad district is one of the backward districts in West Bengal, where about $2 \%$ of India's poor population reside. Healthcare accessibility in this district is always a major issue as most of the inhabitants prefer to gain health services due to poor and inefficient access to medical care. The present study aims to explore the suitable site for medical institution after analysing the present situation of healthcare facilities within the district. For the existing situation of health care facilities, the relative accessibility index (RAI) was calculated by considering no. of medical institutions, no.of patients admitted in a year, and no.of doctors available per day. The result of the existing situation of health care facility reveals that the spatial distribution is not uniform throughout the district (Fig. 2). Hence, for better treatment and getting well service, the resident has to travel another place after crossing a long distance, whereas, many suitable conditions for developing better service have already existed here. The numbers of medical institutions have clustered at the central part of the district i.e. the district capital, Behrampore. As a result, the residents of the other areas are suffered to get better facilities. Thus, the present study was carried out to find suitable locations for health care service by developing a hybrid decision model. For the same, the decision hierarchy was developed using existing facilities of health service, their spatial distance, density and proximity to support the suitable places; where better and well-accommodated health care service would be proposed by considering the local land use and distance to transportation route. After getting selected the proposed sites for local health care service, these are linked with district medical college and hospital located at the central part using shortest path network analysis. This effort will offer better health service to the residents reside at the peripheral part of the district and interlinked with medical college and hospital.

The relative accessibility index (RAI) of present health care service was calculated and the result reveals that only Behrampore (the capital city of the district) block has good RAI, whereas Murshidabad-Jiaganj and Domkal have moderate RAI and all others 23 blocks have low to very low RAI value. Thus, from the overall spatial result of the relative accessibility index, it can be decided that the study area is poor in term of medical facilities and health care services. Thus, looking towards this problematic issue, the present study proposed a hybrid decision model with three tiers of analysis to find suitable places for new health care and shortest distance to interlink with the district medical hospital. The first tier of analysis highlighted the distance, density and proximate of each existing health care to find 


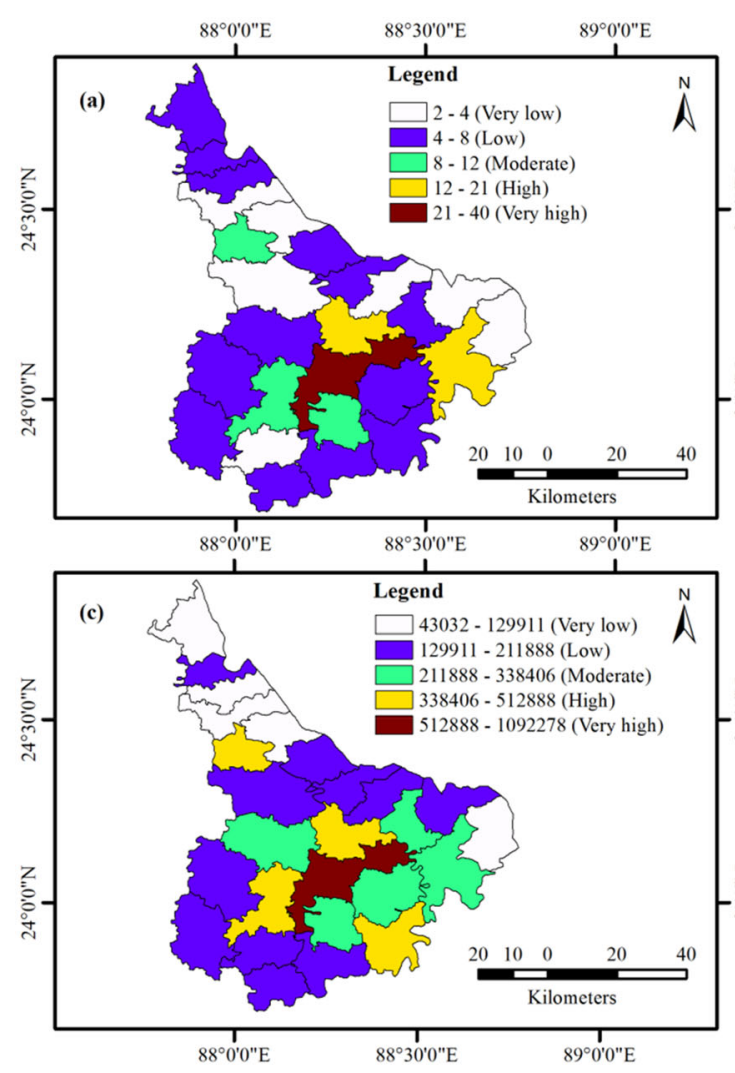

Fig. 2 Existing situations of healthcare services in the study area. Maps showing a Block wise total number of medical institutions available, $\mathbf{b}$ Block wise total number of doctors allocate, $\mathbf{c}$ Block wise total number of patients, $\mathbf{d}$ Relative accessibility index (RAI). Note

more deprived and inaccessible areas in term of health service. The second tier of analysis emphasized to find suitable sites for proposing new health care services based on land use land cover, distance to road, rail, and proximity to residential areas. Finally, the third tier of analysis highlighted the most suitable sites among the proposed health care and network analysis through the shortest path to connect with district medical hospital.

Figure 3a illustrates the prevailing conditions of health care services including medical college, hospital and nursing home. There are only one medical college and hospital is available. There are some other hospitals and nursing home also available both governmental and public but the spatial equality or homogeneity is not found. Figure $3 \mathrm{~b}-\mathrm{d}$ show the distance, density and proximate to present healthcare facilities respectively. The result from each layer of distance, density and proximate reveal that the peripheral parts of the district have always lower facilities. The lower distance to healthcare indicates higher accessibility; lower density of healthcare indicates lower accessibility and closer to healthcare shows higher accessibility. These three spatial layers integrated to consider the accessibility and inaccessibility to healthcare facilities

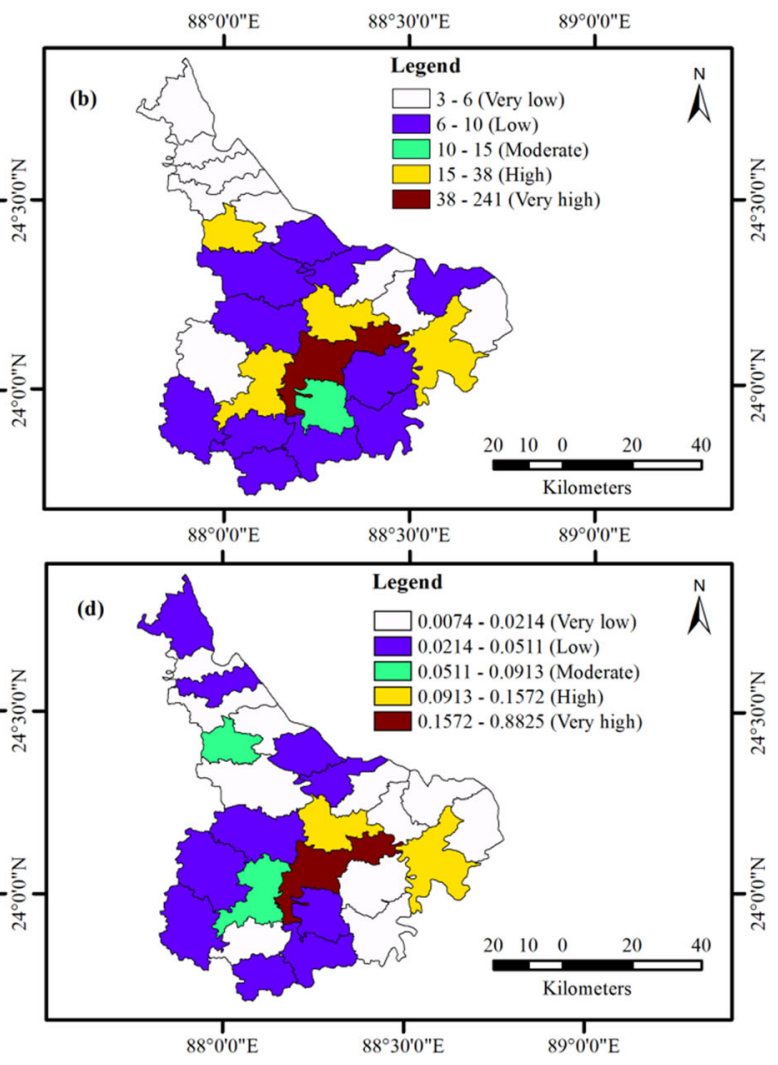

The maps are produced with the help of data illustrated in Table 1. For (a) Medical institutions are both Governmental and public, (c) The number of patients may vary year wise and only the year of 2014-2015 was considered based on the viability of data

throughout the study area. The 1-5 point scale was used for linear combination i.e. 1 for low accessibility (inaccessibility) and 5 for higher accessibility of healthcare facility. Figure 4 shows the overlay result. It depicts the higher and lower spatial accessibility. This result supports the second tier of analysis i.e. to find suitable sites for proposing new healthcare facilities in inaccessible areas.

The suitable sites were considered based on four decision factors. These factors were buffered around the road, buffer around rail, land use land cover and buffer around the settlement (Fig. 5). If the suitable sites for healthcare facilities would locate within $5 \mathrm{~km}$, then it would be considered as more suitable than located far from the road because it will offer higher accessibility in term of travel time as well as travel coast. Any healthcare that is located nearer to the railway, it will be considered as most accessible because of getting immediate and fast service. Land use land cover should be considered before going to choose any space for locating health care. Barren land and agricultural fellow nearer to the settlement would be the best site because this site will offer lower land price, utilization of land, and also getting close to residential areas. The sites that are located within $5 \mathrm{~km}$ distance to populated areas 


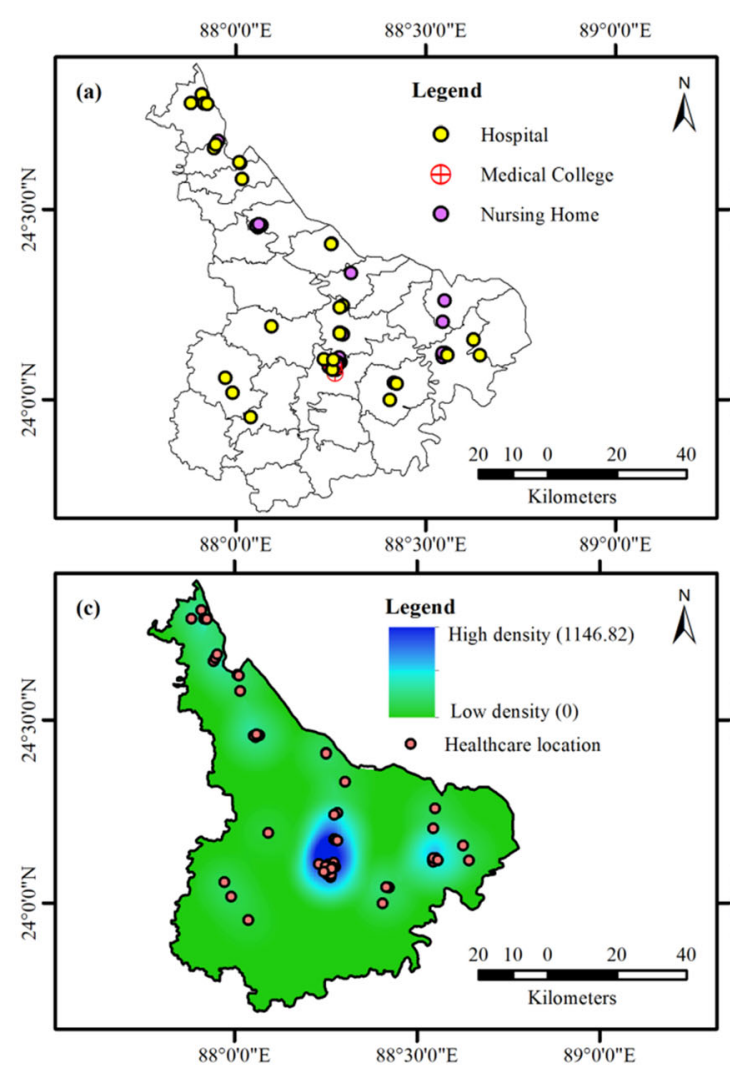

Fig. 3 Factors considered for accessing healthcare accessibility a Location of existing healthcare centres, b Euclidean distance to healthcare, $\mathbf{c}$ Density of healthcare, d Buffer from healthcare $(\mathrm{km})$.

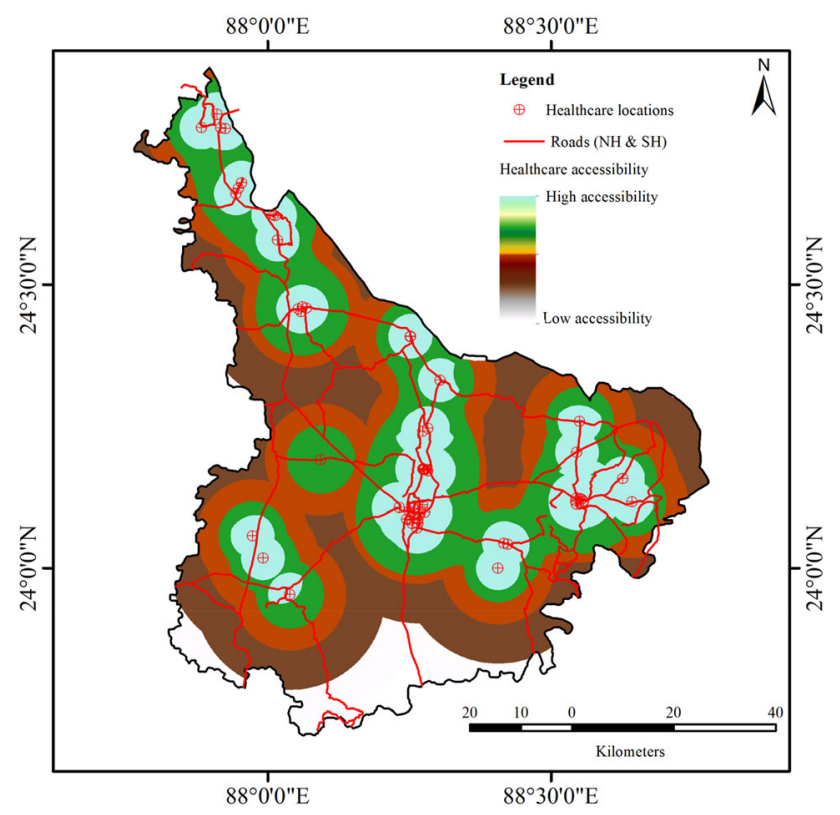

Fig. 4 Healthcare accessibility in Murshidabad. Note This figure is the weighted overlay (equal weight method) of Fig. 3b-d

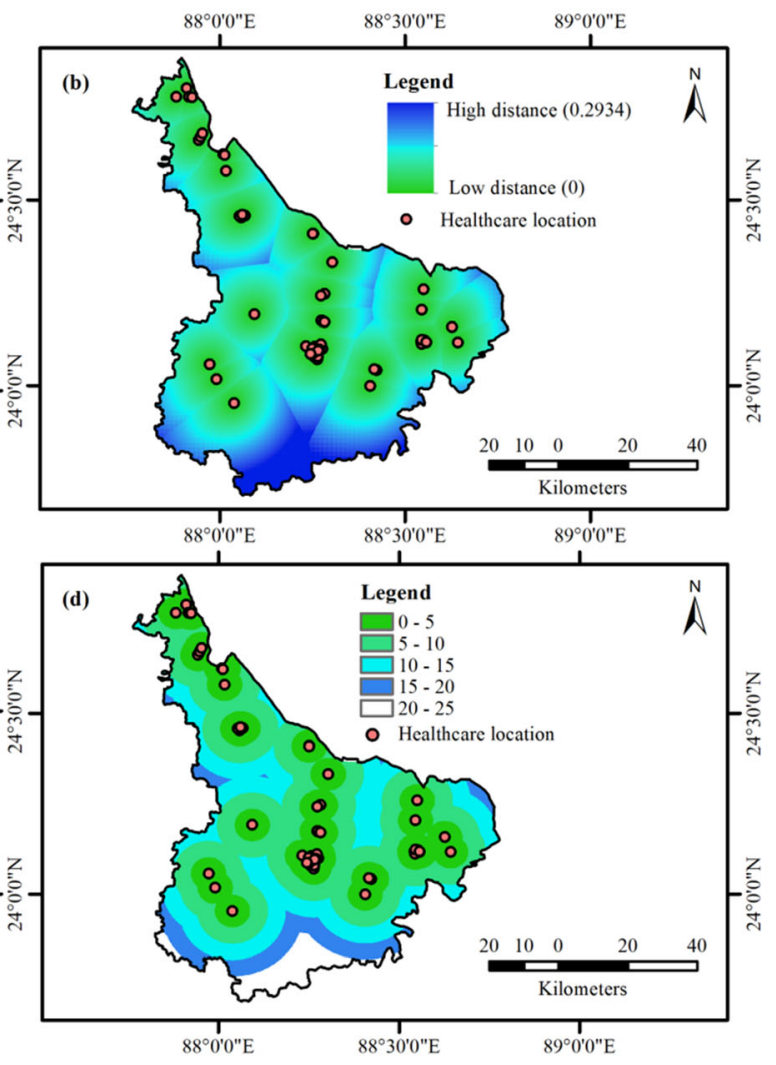

Note High and low value in (b-d) indicate the high and low accessibility to healthcare services based on Euclidean distance, density, and buffer of defined healthcare respectively

will get the best service. Thus, looking towards these conditions, 8 suitable sites were proposed in the present study which can offer health service in inaccessible areas (Fig. 6). The proposed health care in a suitable site can be merged and interlinked with existing health care to make the district enrich and accessible in term of health service. This is figured in supplementary file (S-1). It is essential to validate the location of each proposed site by verifying ground truth. In the present study, site- 1 and site- 3 were validated through the ground visit. But the rest sites were not visited; instead, their ground truth was measured in Google Earth search engine. All sites were selected in open space, barren land or agricultural land, by considering their location nearer to settlement, closer to transportable routes. These ground locations were also plotted in Google Earth search engine, which is shown in Fig. 7.

The technique for order of preference by similarity to ideal solution (TOPSIS) was used to find the ideal best and ideal worst among the proposed sites. The ideal best and the ideal worst value was determined based on the above four decision factors. Thus, for considering the most 


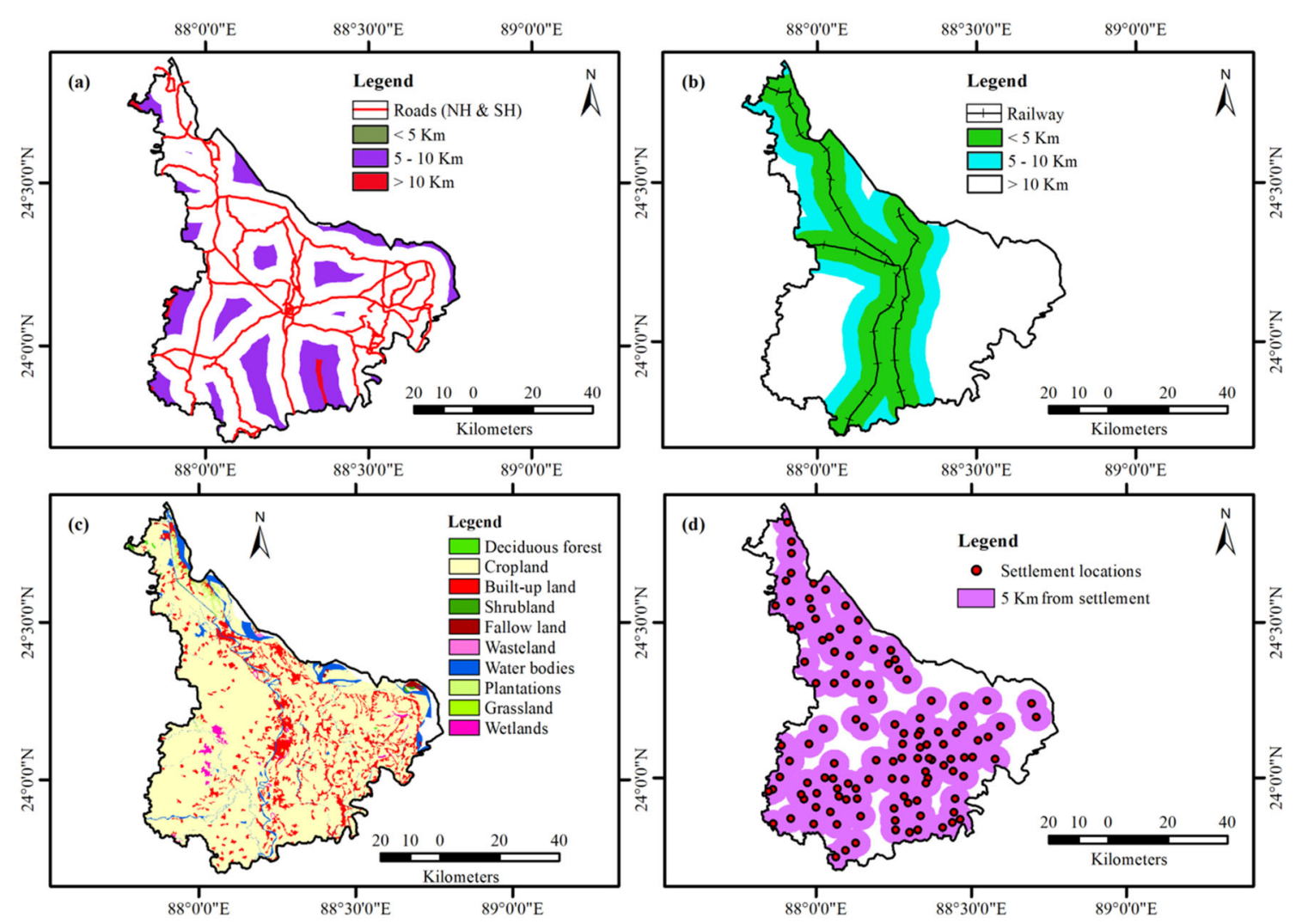

Fig. 5 Decision-making criteria for site suitability analysis of proposed healthcare a Distance from roads, b Distance from railways, c Land use land cover, d $5 \mathrm{~km}$ buffer from settlement areas

suitable site of health care service keeping transportation service, and nearer to residential areas; the lowest distance has given the highest preference. Concomitantly, for land use, the unsuitable land use category has given the lowest preference (Table 3). The result shows that site-1 has the highest preference score $(\mathrm{Pi})$ with 0.81 . This site is far from the district medical college and other health care facilities and resides by a huge number of the rural population and therefore, it is the best site to shape modern health care to serve large people surrounding by connecting district medical college and another hospital on a transfer basis (Figs. 6, 7). Consequently, site- 2 and 7 have the lowest Pi with 0.35 and 0.37 respectively. It is because these sites are within $30 \mathrm{~km}$ from the district medical college, very close to rail and road transportation route and these sites are considered as already accessible. The other selected suitable sites have high to moderate suitability score depends on their location and health service requirements.

Finally, the shortest path network analysis was performed to measure the shortest open street distance and get access to reach district medical college and hospital in case of emergency. This task also supports the requirement to construct a new health care service in a suitable site. Hence, the far distance from district medical college has the highest require score in comparison to located nearer distance. The shortest path network analysis reveals that site- 1 and 5 are located far distance with 64.24 and $47.27 \mathrm{~km}$ respectively which indicate more requirements to manage and construct new health care to offer better service to deprived groups of people. In comparison to site-7 and 4 is much closer with 17.92 and $26.28 \mathrm{~km}$ correspondingly which indicate not a big issue would arise in case of not building new health care facilities (Table 4; Fig. 8).

\section{Discussion}

Health is an important aspect of human existence as well as social well beings. Good service in health can improve the quality of life and progress of a society. But recently, the rapid growth of population and enormous pressure on land, make the service worse. Thus, the present study aimed to emphasize healthcare accessibility issues based on service and accommodation available in the study area. The study area, Murshidabad district is a backward district of West Bengal, India in term of basics infrastructural facilities and amenities [37]. Hence, the present study on healthcare accessibility and site suitability are required to highlight 
Fig. 6 Proposed healthcare sites

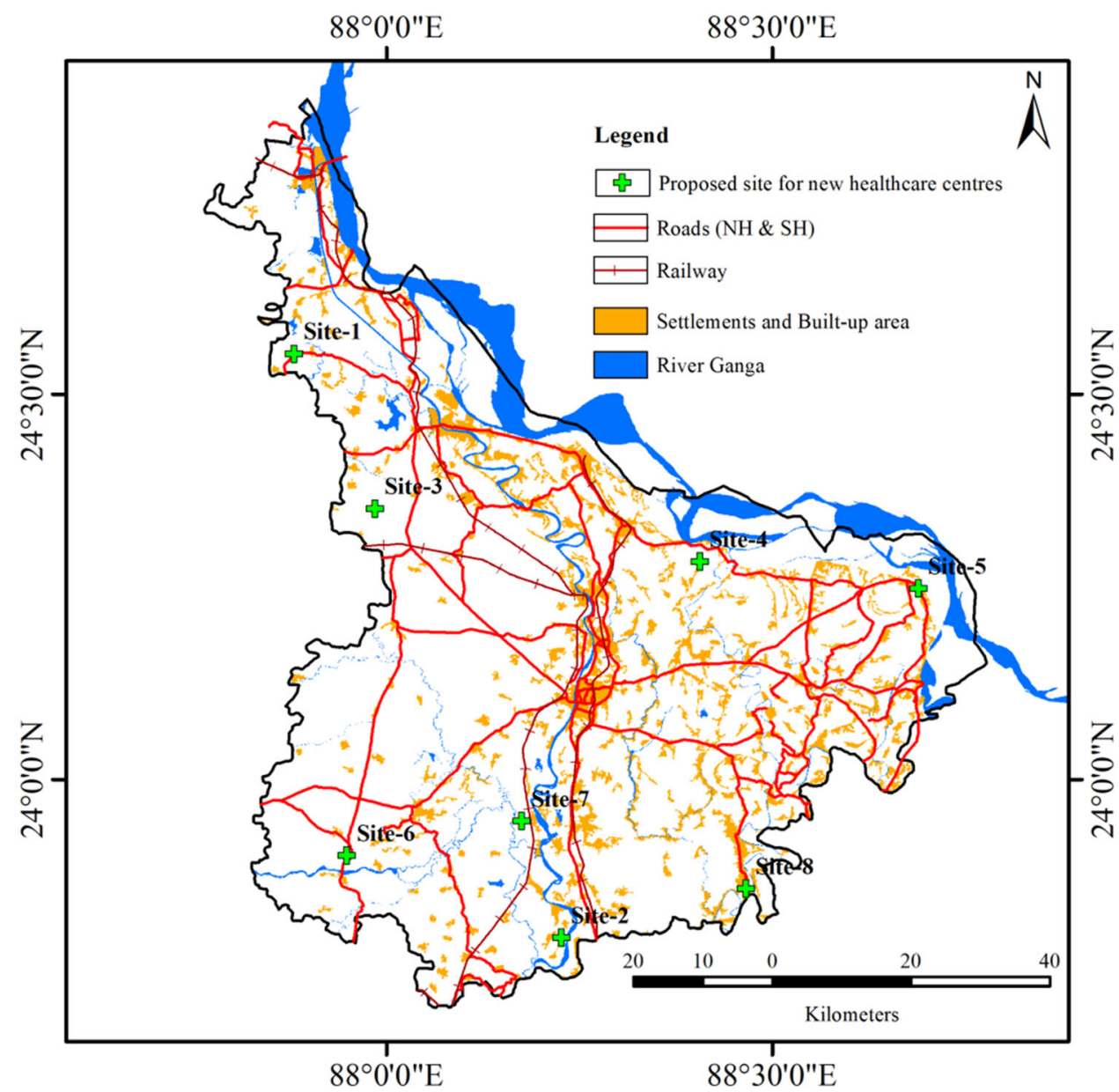

the present situation of healthcare service and necessary measures.

Previous attempts evidenced that several studies defined accessibility in term of availability, accommodation, affordability, and sometimes acceptability [38]. For example, Aday and Andersen [39] defined healthcare accessibility based on the availability of health services with special reference to financial, informational, and behavioural influences. Unlike, Gulliford et al. [40] focused on health demand by highlighting differentiation between having access to healthcare and gaining access to healthcare for overcoming the financial and organizational barriers from health service. All in all, other studies also evidenced common factors for determining healthcare accessibility like (1) spatial distribution of healthcare facilities; (2) transportation facilities and distance to healthcare centres; (3) socio-economic conditions of nearing population group; and (4) accommodation available in healthcare centres [41]. Based on these above-mentioned factors; recently, major concerns have been giving on geographic information system (GIS) applications in the field of healthcare accessibility due to its efficiency and accuracy in spatial as well as non-spatial analysis [38, 42].
Site suitability is another aspect of the healthcare facility, in which major concerns have given towards suitable locations for constructing new healthcare to provide better service to target groups as well as overcome unequal distribution problems of healthcare service. Site suitability is based on multi-factor analysis because searching and locating healthcare in suitable places are depended on more than one factor [43]. Many studies carried out in the field of site suitability of healthcare using GIS and multi-criteria techniques. Such as the optimum site selection for a hospital in Tehran using a geographical information system [44]; the suitable site of a regional hospital in Taiwan using analytic hierarchy process, sensitivity analysis, and Delphi method [45].

But previously it was not attempted to analysis healthcare site suitability by considering accessibility first. Poor accessibility needs proposing new healthcare. So, it is essential to analysis accessibility first for proposing and constructing of new healthcare, which is covered in this study. Unlike many studies only highlighted healthcare accessibility [39-41] or site suitability [44, 45], the present study considered these inter-connected factors by developing a hybrid model. From that point of view, this study is 

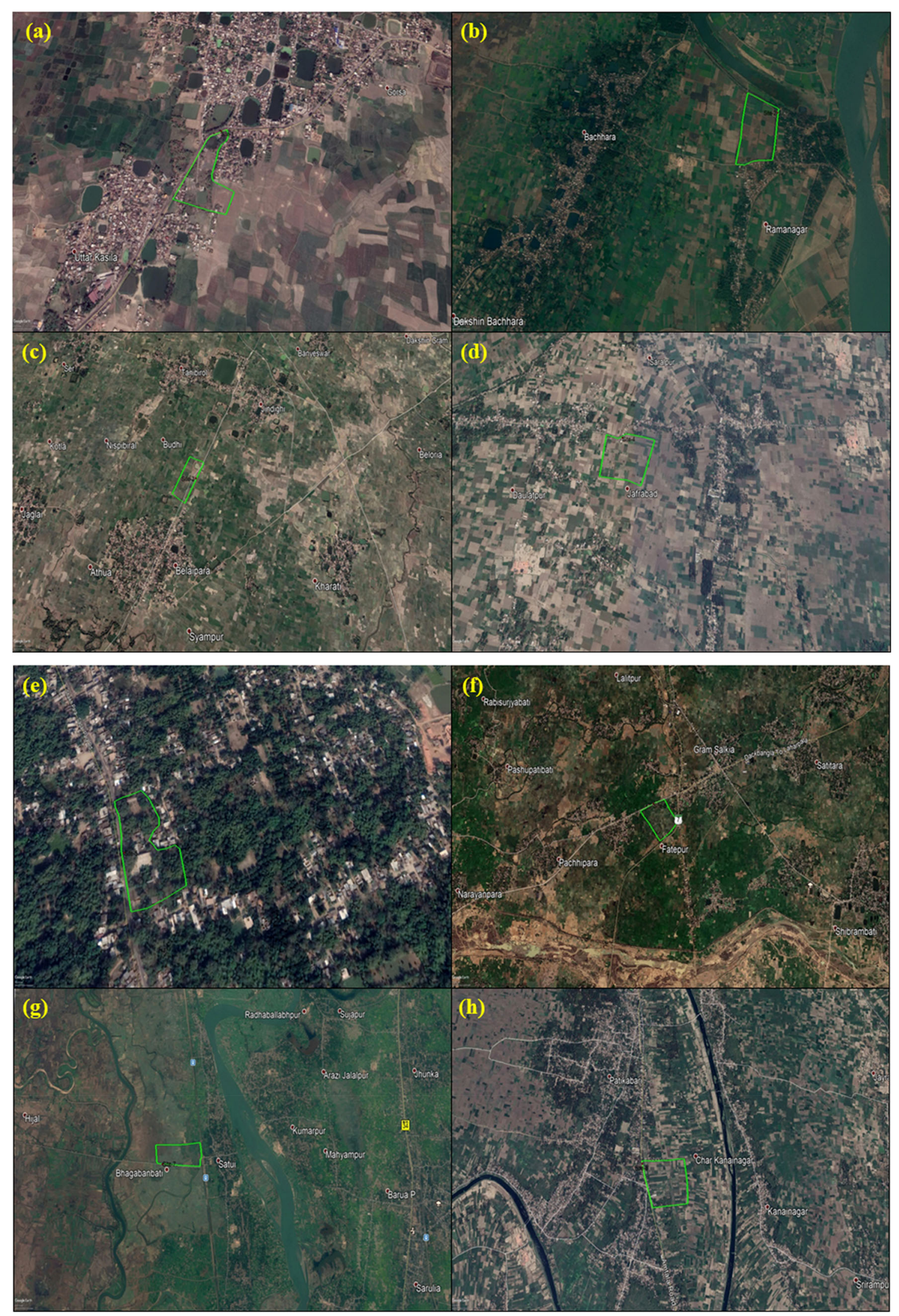
4Fig. 7 The ground truth areas of proposed healthcare sites after suitability analysis a Site-1: considered as best site and urgent require for new healthcare, this site is $1.50 \mathrm{~km}$ from Rajgram rail station, surrounded by dense rural population and no healthcare facilities nearby, b Site-2: very close to NH34 and located in a sparse populated areas, c Site-3: far away from NH34, NH60 and railway junction, d Site-4: $11.50 \mathrm{~km}$ from Bhagwangola railway station and located in a densely populated areas, e Site-5: very close to Ganga river and Sagar Para road, also located near many densely settlement areas, f Site-6: locate at south-west corner of the district and very close to SH7, g Site-7: this site is very close to district medical college and hospital, h Site-8: just beside SH14, Goghata bus stoppage and about $9.0 \mathrm{~km}$ from Ramel health destination

unique and no similar studies ever carried out before. The present study would be useful to health planner in the study area as well as other regions also with similar geographical settings for defining inaccessible areas and locating suitable sites for better health service.

\section{Conclusions}

While many previous researchers have highlighted the nonspatial data and statistical inference to analyse healthcare accessibility in a geographical location, the present study applied a GIS-based hybrid decision-making approach for assessing the spatial accessibility of healthcare facilities and site suitability analysis in Murshidabad district of West Bengal, India. This study offered a hybrid decision-making approach for proposing suitable sites regarding better healthcare service. To provide better service and reach a deprived group of people, a pipe dream was prepared that needs for logical decision making and resolve existing problems. The result reveals that spatial discrepancy exists in case of access to healthcare facilities. The location of existing healthcare primarily clusters in the central and northern portions. The distance, density and proximate analysis of these healthcares explored the spatial inaccessible areas. To achieve equal access, allocation of new healthcare is essential to reduce the spatial disparity. Thus, the equal weight-based weighted linear combination was performed using land use, proximity to road and rail, and distance to residential areas to support suitable site for determining and allocating new healthcare facilities.

Decision support system with GIS integration offered 8 suitable sites in inaccessible areas. Poor accessibility and poor health services in an area increase health and social disparities. Hence, the urgent requirement is needed to increase accessibility. The present study emphasized the same issue and developed a hybrid approach to integrate

Table 3 TOPSIS decision matrix for measuring performance score based on ideal best and ideal worst value

\begin{tabular}{|c|c|c|c|c|c|c|c|c|c|}
\hline & $\begin{array}{l}\text { Buffer } \\
\text { around road }\end{array}$ & $\begin{array}{l}\text { Buffer } \\
\text { around rail }\end{array}$ & $\begin{array}{l}\text { Land use } \\
\text { land cover }\end{array}$ & $\begin{array}{l}\text { Buffer } \\
\text { around } \\
\text { settlement }\end{array}$ & $\begin{array}{l}\text { Ideal } \\
\text { best } \\
\left(\mathrm{Si}^{+}\right)\end{array}$ & $\begin{array}{l}\text { Ideal } \\
\text { worst } \\
\left(\mathrm{Si}^{-}\right)\end{array}$ & $\begin{array}{l}\text { Performance } \\
\text { score Pi }\end{array}$ & Rank & $\begin{array}{l}\text { Suitability } \\
\text { score }\end{array}$ \\
\hline Site-1 & 1 & 2 & 5 & 4 & 0.0391 & 0.1762 & 0.8183 & 1 & 8 \\
\hline Site-2 & 3 & 4 & 2 & 3 & 0.1309 & 0.0733 & 0.3590 & 8 & 1 \\
\hline Site-3 & 2 & 3 & 4 & 3 & 0.0721 & 0.1305 & 0.6442 & 4 & 5 \\
\hline Site-4 & 4 & 3 & 4 & 4 & 0.1108 & 0.0998 & 0.4739 & 6 & 3 \\
\hline Site-5 & 2 & 1 & 3 & 4 & 0.0615 & 0.1576 & 0.7195 & 2 & 7 \\
\hline Site-6 & 3 & 1 & 3 & 4 & 0.0788 & 0.1441 & 0.6465 & 3 & 6 \\
\hline Site-7 & 5 & 5 & 5 & 3 & 0.1677 & 0.1005 & 0.3747 & 7 & 2 \\
\hline Site- 8 & 3 & 1 & 1 & 4 & 0.1156 & 0.1356 & 0.5400 & 5 & 4 \\
\hline
\end{tabular}

Table 4 Network analysis of proposed suitable healthcare sites and respective distance

\begin{tabular}{lll}
\hline Input ID & Target ID & Distance $(\mathrm{km})$ \\
\hline Murshidabad Medical College \& Hospital & Site-1 & 64.24 \\
Murshidabad Medical College \& Hospital & Site-2 & 32.66 \\
Murshidabad Medical College \& Hospital & Site-3 & 40.26 \\
Murshidabad Medical College \& Hospital & Site-4 & 26.28 \\
Murshidabad Medical College \& Hospital & Site-5 & 47.27 \\
Murshidabad Medical College \& Hospital & Site-6 & 37.74 \\
Murshidabad Medical College \& Hospital & Site-7 & 17.92 \\
Murshidabad Medical College \& Hospital & Site-8 & 33.09
\end{tabular}


Fig. 8 Shortest path network analysis (shortest route from proposed healthcare to district medical college)

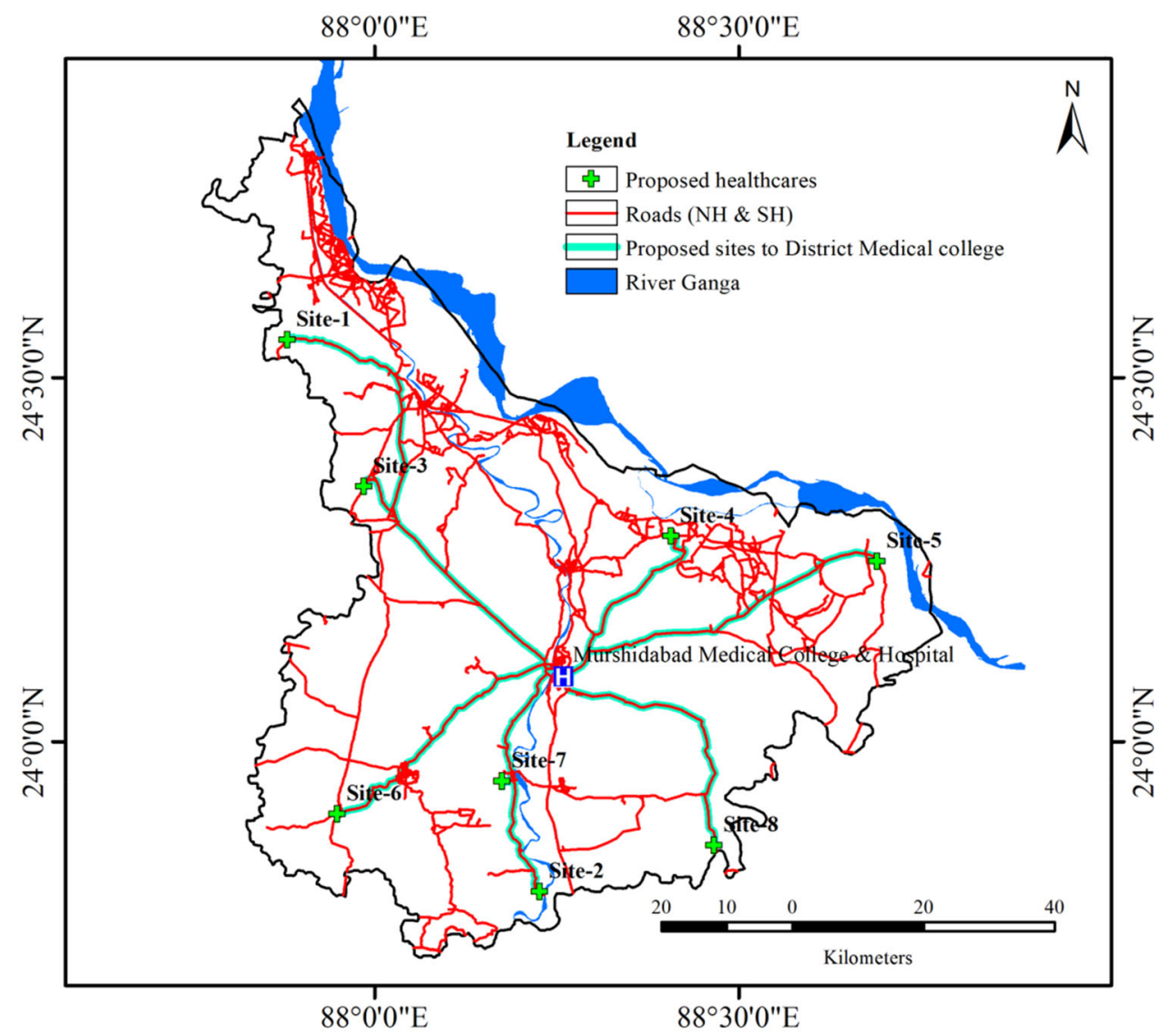

multiple factors to propose sites for new healthcare facilities and remove spatial disparity in the study area. The advantages of developing and using a hybrid model are (1) it integrates different models and approach, (2) it increases the accuracy of the result and reduces the drawbacks of single model and method, (3) it interlinks two or more aspects of a study, for instance, in case of the present study using a hybrid model two aspects, i.e. accessibility to healthcare and site suitability of healthcare have been determined, and (4) hybrid model helps in simplifying the complex relationship of among criteria or perspective. However, a hybrid model also suffers from some disadvantages, like (1) it is more complex to apply (2) the preparation of model take more times than single model (3) sometimes it also suffers from overfitting etc. Therefore, removing such disadvantages and adopting the abovementioned advantages, the present proposed and used a hybrid model to show healthcare accessibility and site suitability. This study would appear like a good source of health service enhancement and plan implementation to policymakers and health planners. Recently, not only our country but the world worried about the outbreak of 'novel coronavirus'. The government truly finds enormous space for 'isolation' service. Globally 2,193,558 confirmed cases are reported (till 17.04.2020). India is no exception in this case, where, 13,495 confirmed cases are identified. It is assumed that Murshidabad is also too much vulnerable as there is a lack of basic infrastructure. Therefore, in this regards, it is recommended that Government and local planners can start medical emergency in proposed sites with primary equipment and service to reach target population groups. On getting success in the mission, modern infrastructural development and service could be proposed afterwards.

Acknowledgements We thankfully acknowledge the anonymous three reviewers and the Editor in Chief for their valuable time, productive comments and suggestions for enlightening the overall quality of our manuscript.

Funding No fund was received from any sources.

Compliance with ethical standards

Conflict of interest On behalf of all authors, the corresponding author states that there is no conflict of interest.

\section{References}

1. Rekha, R. S., Wajid, S., Radhakrishnan, N., \& Mathew, S. (2017). Accessibility analysis of health care facility using geospatial 
techniques. Transportation Research Procedia, 27, 1163-1170. https://doi.org/10.1016/j.trpro.2017.12.078.

2. UNDESA. (2015). UN chief urges greater efforts to improve health and well-being of indigenous peoples. United Nations Department of Economic and Social Affairs.

3. WHO. (2017). Human rights and health. World Health Organisation

4. President's Commission for the Study of Ethical Problems in Medicine and Biomedicine and Behavioral Science Research. (1983). Securing access to health care: The ethical implications of differences in the availability of health services (Vol. 1). Washington, DC: President's Commission.

5. Organisation for Economic Co-operation and Development, and The World Bank. (2018). Delivering quality health services: A global imperative for universal health coverage. Geneva: World Health Organization. Licence: CC BY-NC-SA 3.0 IGO. Retrieved on March 29, 2020, from https://extranet.who.int/sph/ docs/file/1654.

6. Nghiem, S., \& Connelly, L. (2017). Convergence and determinants of health expenditures in OECD countries. Health Economics Review, 7, 29. https://doi.org/10.1186/s13561-017-01644.

7. Kea, X., Saksenaa, P., \& Holly, A. (2011). The determinants of health expenditure: A country-level panel data analysis. Geneva: World Health Organization. Retrieved from March 29, 2020, from https://www.who.int/health_financing/documents/report_ en_11_deter-he.pdf.

8. Baru, R., et al. (2010). Inequities in access to health services in India: Caste, class and region. Economic and Political Weekly, 45(38), 49-58.

9. Qadeer, I. (2011). The challenge of building rural health services. Indian Journal of Medical Research, 134, 591-593.

10. Cabrera-Barona, P., Blaschke, T., \& Gaona, G. (2018). Deprivation, healthcare accessibility and satisfaction: Geographical context and scale implications. Applied Spatial Analysis, 11, 313-332. https://doi.org/10.1007/s12061-017-9221-y.

11. Higgs, G. (2004). A literature review of the use of GIS-based measures of access to health care services. Health Services and Outcomes Research Methodology, 5(2), 119-139. https://doi.org/ 10.1007/s10742-005-4304-7.

12. Delamater, P. L., Messina, J. P., Shortridge, A. M., \& Grady, S. C. (2012). Measuring geographic access to health care: Raster and network-based methods. International Journal of Health Geographics, 11(1), 15. https://doi.org/10.1186/1476-072X-1115.

13. McGrail, M. R., \& Humphreys, J. S. (2014). Measuring spatial accessibility to primary health care services: Utilising dynamic catchment sizes. Applied Geography, 54, 182-188. https://doi. org/10.1016/j.apgeog.2014.08.005.

14. Wang, J., Deng, Y., Song, C., \& Tian, D. (2016). Measuring time accessibility and its spatial characteristics in the urban areas of Beijing. Journal of Geographical Sciences, 26(12), 1754-1768. https://doi.org/10.1007/s11442-016-1356-2.

15. Penchansky, R., \& Thomas, J. W. (1981). The concept of access: Definition and relationship to consumer satisfaction. Medical Care, 19, 127-140.

16. Khan, A. A. (1992). An integrated approach to measuring potential spatial access to health care services. Socio-economic Planning Sciences, 26(4), 275-287. https://doi.org/10.1016/00380121(92)90004-O.

17. Geurs, K. T., \& Wee, B. V. (2004). Accessibility evaluation of land-use and transport strategies: Review and research directions. Journal of Transport Geography, 12(2), 127-140. https://doi.org/ 10.1016/j.jtrangeo.2003.10.005.

18. Luo, W., \& Wang, F. (2003). Measures of spatial accessibility to health care in a GIS environment: Synthesis and a case study in the Chicago region. Environment and Planning B: Planning and Design, 30, 865-884. https://doi.org/10.1068/b29120.

19. Pan, X., Kwan, M.-P., Yang, L., Zhou, S., Zuo, Z., \& Wan, B. (2018). Evaluating the accessibility of healthcare facilities using an integrated catchment area approach. International Journal of Environmental Research and Public Health, 15(9), 20-51. https:// doi.org/10.3390/ijerph15092051.

20. Higgs, G., \& Gould, M. (2001). Is there a role for GIS in the 'New NHS'? Health and Place, 7(3), 247-259. https://doi.org/10. 1016/s1353-8292(01)00014-4.

21. Cromley, E. K., \& McLafferty, S. L. (2002). GIS and public health. New York: Guilford Press.

22. Bamford, E. J., Dunne, L., Taylor, D. S., Symon, B. G., Hugo, G. J., \& Wilkinson, D. (1999). Accessibility to general practitioners in rural South Australia: A case study using geographic information system technology. Medical Journal of Australia, 171(11-12), 614-616. https://doi.org/10.5694/j.1326-5377.1999. tb123821.x.

23. Fortney, J., Rost, K., Zhang, M., \& Warren, J. (1999). The impact of geographic accessibility on the intensity and quality of depression treatment. Medical Care, 37(9), 884-893. https://doi. org/10.1097/00005650-199909000-00005.

24. Jones, A. P., Bentham, G., Harrison, B. D. W., Jarvis, D., Badminton, R. M., \& Wareham, N. J. (1998). Accessibility and health service utilization for asthma in Norfolk, England. Journal of Public Health, 20(3), 312-317. https://doi.org/10.1093/oxford journals.pubmed.a024774.

25. Population Census. (2011). Retrieved from December 23, 2019, from https://www.Census2011.co.in.

26. District Statistical Handbook. (2014). Murshidabad district, Bureau of Applied Economics \& Statistics, Department of Statistics \& Programme Implementation, Govt. of West Bengal. Accessed November 13, 2018, from https://www.wbpspm.gov.in/ publications/District\%20Statistical\%20Handbook.

27. Office of the $\mathrm{CMOH}$, Murshidabad. (2019). Retrieved December 2, 2019, from http://www.murshidabad.gov.in/Section/CMOH. aspx.

28. Silverman, B. W. (1986). Density estimation for statistics and data analysis. New York: Chapman and Hall.

29. Ghosh, P., \& Lepcha, K. (2018). Weighted linear combination method versus grid based overlay operation method-A study for potential soil erosion susceptibility analysis of Malda district (West Bengal) in India. The Egyptian Journal of Remote Sensing and Space Science. https://doi.org/10.1016/j.ejrs.2018.07.002.

30. Jankowski, P. (1995). Integrating geographical information systems and multiple criteria decision making methods. International Journal of Geographical Information Systems, 9(3), 251-273. https://doi.org/10.1080/02693799508902036.

31. Ali, S. A., \& Ahmad, A. (2018). Using analytic hierarchy process with GIS for Dengue risk mapping in Kolkata Municipal Corporation, West Bengal. Spatial Information Research. https://doi. org/10.1007/s41324-018-0187-x.

32. Ali, S. A., \& Ahmad, A. (2019). Spatial susceptibility analysis of vector-borne diseases in KMC using geospatial technique and MCDM approach. Modeling Earth Systems and Environment. https://doi.org/10.1007/s40808-019-00586-y.

33. Ali, S. A., \& Ahmad, A. (2019). Mapping of mosquito-borne diseases in Kolkata Municipal Corporation using GIS and AHP based decision making approach. Spatial Information Research. https://doi.org/10.1007/s41324-019-00242-8.

34. Shahba, S., Arjmandi, R., Monavari, M., \& Ghodusi, J. (2017). Application of multi-attribute decision-making methods in SWOT analysis of mine waste management (case study: Sirjan's Golgohar iron mine, Iran). Resources Policy, 51, 67-76. https:// doi.org/10.1016/j.resourpol.2016.11.002. 
35. Chen, M Sh, Lin, M Ch., Wang, Ch Ch., \& Chang, C. A. (2009). Using HCA and TOPSIS approaches in personal digital assistant menu-icon interface design. International Journal of Industrial Ergonomics, 39(5), 689-702. https://doi.org/10.1016/j.ergon. 2009.01.010.

36. Jahanshahloo, G. R., Lofti, F. H., \& Izadikhah, M. (2006). An algorithmic method to extend TOPSIS for decision making problems with interval data. Applied Mathematics and Computation, 175(2), 1375-1384. https://doi.org/10.1016/j.amc.2005.08. 048.

37. Parvin, F., Hashmi, S. N. I., \& Ali, S. A. (2019). Appraisal of infrastructural amenities to analyze spatial backwardness of Murshidabad district using WSM and GIS-based kernel estimation. GeoJournal. https://doi.org/10.1007/s10708-019-10057-7.

38. Murad, A. (2018). Using GIS for determining variations in health access in Jeddah City, Saudi Arabia. ISPRS International Journal of Geo-Information, 7(7), 254. https://doi.org/10.3390/ ijgi7070254.

39. Aday, L. A., \& Andersen, R. A. (1974). Framework for the study of access to medical care. Health Services Research, 9, 208-220.

40. Gulliford, M., Figueroa-Munoz, J., Morgan, M., Hughes, D., Gibson, B., Beech, R., et al. (2002). What does 'access to health care' mean? Journal of Health Services Research \& Policy, 7, 186-188.
41. Higgs, G. A. (2005). Literature review of the use of GIS-based measures of access to health care services. Health Services and Outcomes Research Methodology, 5, 119-139.

42. Mushonga, H. T., Banda, F., \& Mulolwa, A. (2017). Development of a web based GIS for health facilities mapping, monitoring and reporting: A case study of the Zambian Ministry of health. South African Journal of Geomatics, 6, 321-332.

43. Ali Soltani, A., \& Marandi, E. Z. (2011). Hospital site selection using two-stage fuzzy multi-criteria decision making process. Journal of Urban and Environmental Engineering, 5(1), 32-43. https://doi.org/10.4090/juee.2011.v5n1.032043.

44. Vahidnia, M. H., Alesheikh, A. A., \& Alimohammadi, A. (2009). Hospital site selection using fuzzy AHP and its derivatives. Journal of Environmental Management, 90(10), 3048-3056. https://doi.org/10.1016/j.jenvman.2009.04.010.

45. Wu, C. R., Lin, C. T., \& Chen, H. C. (2007). Optimal selection of location for Taiwanese hospitals to ensure a competitive advantage by using the analytic hierarchy process and sensitivity analysis. Building and Environment, 42(3), 1431-1444. https:// doi.org/10.1016/j.buildenv.2005.12.016.

Publisher's Note Springer Nature remains neutral with regard to jurisdictional claims in published maps and institutional affiliations. 